\title{
Determinants of Cough Efficiency in Duchenne Muscular Dystrophy
}

\author{
Antonella LoMauro, Msc, ${ }^{1}$ Marianna Romei, $\mathrm{PhD}^{2}{ }^{2}$ Maria Grazia D’Angelo, $\mathrm{MD} \mathrm{PhD},{ }^{2}$ \\ and Andrea Aliverti, $\mathrm{PhD}^{1 *}$
}

\section{INTRODUCTION}

Duchenne muscular dystrophy (DMD) is an X-linked recessive hereditary disease that affects both skeletal and cardiac muscle over time. With the progression of the disease and the deterioration of respiratory muscles function, cough, that is the ability to clear the airway of secretions, becomes critical. Respiratory muscle weakness, impaired secretion clearance, and mucus plugging further compromise chest infections resulting in recurrent episodes of atelectasis, pneumonia, and respiratory insufficiency. ${ }^{1,2}$ Several factors conspire to diminish the effectiveness of cough in DMD patients: the neuromuscular weakness of inspiratory muscles, ${ }^{3}$ limiting the depth of pre-cough inspiration, and expiratory muscles in association with chest wall distortion from scoliosis resulting in reduced intrathoracic expiratory pressures and flows. ${ }^{4}$ The assessment of cough effectiveness considers a set of different functional parameters obtained from both noninvasive and invasive volitional tests. The former include the assessment of peak cough flow (PCF), spirometric indexes as Forced Vital Capacity (FVC) and

\footnotetext{
${ }^{1}$ TBM Lab, Dipartimento di Elettronica, Informazione e Bioingegneria, Politecnico di Milano, Milano, Italy.

${ }^{2}$ IRCCS E.Medea, Bosisio Parini (Lc), Italy.

${ }^{*}$ Correspondence to: Andrea Aliverti, PhD, TBM Lab, Dipartimento di Elettronica, Informazione e Bioingegneria, Politecnico di Milano, P.zza L. da Vinci, 32, 20133 Milano, Italy. E-mail: andrea.aliverti@ polimi.it

Received 11 January 2013; Accepted 18 May 2013.

Published online 14 July 2013
} 
Forced Expiratory Volume in one second $\left(\mathrm{FEV}_{1}\right){ }^{5}$ maximal inspiratory and expiratory pressures (MIP and MEP), ${ }^{6,7}$ the latter maximal cough gastric pressure. ${ }^{8}$

Among these parameters, PCF is the most commonly used in the clinical practice. DMD patients with PCF $>270 \mathrm{~L} / \mathrm{min}$ are felt to have an adequate cough whereas PCF $<160 \mathrm{~L} / \mathrm{min}$ is associated with inefficient cough, ${ }^{9}$ unable to provide enough mucociliary clearance. When PCF is $160-270 \mathrm{~L} / \mathrm{min}$, cough is considered adequate when patients are well, but is likely to fall below 160 during chest infection and viral illness. ${ }^{10}$

Despite the relevance of the problem, however, there is scanty literature describing the mechanisms that determine inefficient cough in DMD patients.

As in healthy subjects the volume inspired prior to coughing significantly influences the mechanical changes during the expiratory phase of coughing and therefore $\mathrm{PCF},{ }^{11}$ one possible cause of inefficient cough in DMD is the reduced inspired volume preceding cough (namely, "operating" lung or chest wall volume) secondary to weakened inspiratory muscles. The aim of the present study was to investigate if thoraco-abdominal operating volumes during coughing determine the effectiveness of cough in DMD patients. Furthermore, as the abdominal contribution to tidal volume during spontaneous breathing is, in these patients, a strong indicator of diaphragmatic impairment ${ }^{12}$ and a predictor of the onset of nocturnal desaturation, ${ }^{13}$ we hypothesized that this parameter could also represent a non-volitional and noninvasive index discriminating efficient and inefficient cough.

\section{MATERIALS AND METHODS}

\section{Subjects}

Thirty-six DMD subjects attending IRCCS "E. Medea" Institute as inpatients for periodic clinical assessment and 15 age-matched healthy male subjects recruited as controls were included in the study. Patients were included if they were able to perform reliable PCF measurements and if their facial muscle strength was enough to allow reliable measurements through the mouthpiece. In all patients, clinical information including mutations in the DMD gene, use of noninvasive mechanical ventilation and cough assistive devices, episodes of upper or lower airways infection in the last year, use of steroids, cardiac dysfunction, severity of scoliosis, and spinal fusion were recorded. Patients were identified for use of cough assisted techniques if their peak cough flow was $<270 \mathrm{~L} / \mathrm{min}$; while the indications for noninvasive ventilation were $\mathrm{FVC}<40 \%$ and percentages of the night-time spent with arterial oxygen desaturation $>10 \% .{ }^{14}$ All patients with heart dysfunction received beta blockers and ACE inhibitors treatment.

All subjects or parents signed a written informed consent form, as approved by the Local Ethical
Committee of IRCCS "E. Medea" Institute. The study was approved by the Institute's Human Ethics Committee according to the declaration of Helsinki.

\section{Measurements and Protocol}

Routine evaluation of respiratory function, that is spirometry, pulse oximetry, maximal respiratory pressures, and PCF measurements was performed following the guidelines for respiratory muscles testing. ${ }^{15-17}$

\section{Pulmonary Function Tests}

Measurements of FVC, $\mathrm{FEV}_{1}$, subdivision of lung volumes (Functional Residual Capacity, FRC; Residual Volume, RV; and Total Lung Capacity, TLC) by the nitrogen washout technique were performed $\left(\mathrm{V}_{\max }\right.$ series 22, SensorMedics, Yorba Linda, CA). Predicted values were derived from published data. ${ }^{18}$ Nocturnal oxygen saturation $\left(\mathrm{SpO}_{2}\right)$ was measured using a digital pulse oximeter (Nonin, 8500 digital pulse oximeter Quitman, TX).

\section{Respiratory Muscle Strength}

Maximal respiratory pressures were measured at the mouth (MicroRPM; Micro Medical Ltd., Rochester, England). Maximal expiratory pressure (MEP) and maximal inspiratory pressure (MIP) were performed starting respectively from TLC and RV and the effort was maintained for at least one second. The best MEP and MIP values in two or more attempts were chosen.

\section{Peak Cough Flow}

Unassisted PCF was measured by a portable peak flowmeter (Vitalograph, Ennis, Ireland). Patients were asked to cough as much as possible at least twice and the highest value in each test was chosen.

\section{Opto-Electronic Plethysmography (OEP)}

Total and compartmental chest wall volumes were measured by Opto-Electronic Plethysmography (OEP System; BTS, Milan, Italy). The system, based on eight infrared video cameras working at a sampling rate of $60 \mathrm{~Hz}$, computes the 3D coordinates of 52 retro-reflective markers placed, according to specific anatomical points, over the anterior chest wall surface of the subject lying supine (Fig. 1). After a quiet breathing period of stabilization, patients and healthy controls were asked to perform three single maximal voluntary cough maneuvers separated by at least 4 or 5 breaths in supine position. No specific instructions regarding operating volume were given to the subjects. For each subject, the cough maneuver with maximal inspired chest wall volume was considered for further analysis. 


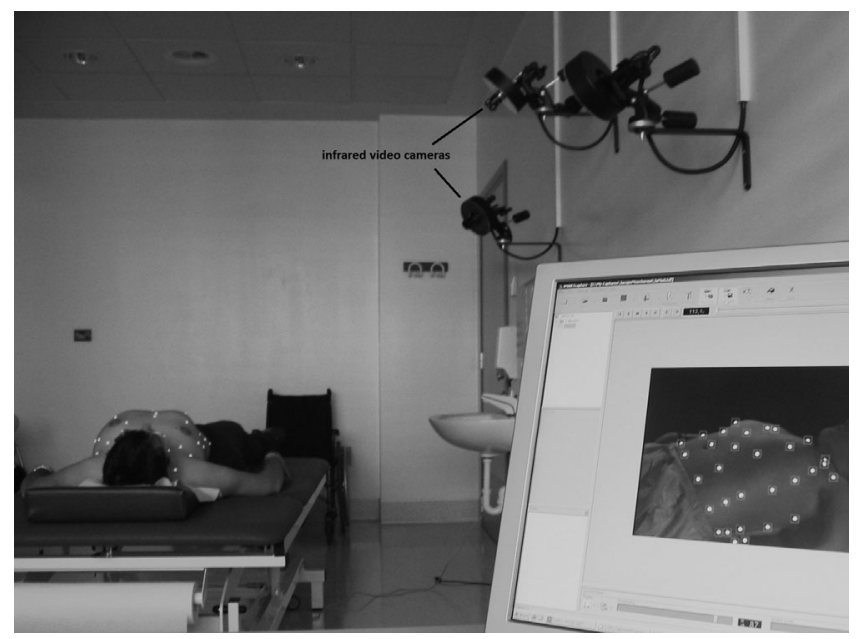

Fig. 1. Experimental set-up for the analysis of chest wall volumes in supine position via opto-electronic plethysmography in a DMD patient.

The volume of total chest wall $\left(\mathrm{V}_{\mathrm{CW}}\right)$ and its two compartments, rib cage $\left(\mathrm{V}_{\mathrm{RC}}\right)$, and abdomen $\left(\mathrm{V}_{\mathrm{AB}}\right)$, were noninvasively measured by OEP. The points of start of inspiration, end of inspiration and end of cough were identified on $\mathrm{V}_{\mathrm{CW}}$, as shown in Figure 2, and on the two compartments at the same instants. Tidal volume $\left(\mathrm{V}_{\mathrm{T}}\right)$, as the average of total $\mathrm{V}_{\mathrm{CW}}$ variations, and its percentage contribution of $\mathrm{V}_{\mathrm{AB}}$ were computed during the spontaneous breaths preceding cough (Fig. 2).

\section{Subdivision of DMD Patients' Group}

The DMD population was subdivided into three groups according to PCF, namely patients with inefficient cough ( $\mathrm{PCF}<160 \mathrm{~L} / \mathrm{min})$, adequate cough $(\mathrm{PCF}>270 \mathrm{~L} / \mathrm{min})$, and adequate cough when they are well $(160<\mathrm{PCF}$ $<270 \mathrm{~L} / \mathrm{min})$.

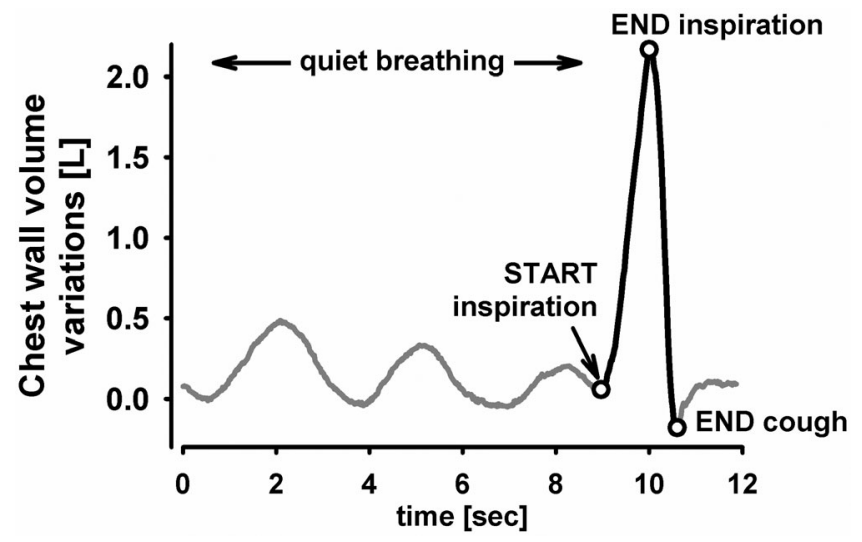

Fig. 2. Time course of total chest wall volume variation during a period of quiet breathing (grey) followed by a single voluntary cough maneuver (black) in a representative healthy control subject. Open symbols indicate the points of start inspiration, end inspiration and end cough used for the analysis.

\section{Statistical Analysis}

Comparisons between groups were conducted using a one-way Analysis of Variance (ANOVA) with cough efficiency as independent factor. Post-hoc tests were based on Holm-Sidak or Dunn's method. Receiver Operating Characteristic (ROC) curve analysis was performed to compare the diagnostic performance of those parameters that resulted significantly different between inefficient and adequate cough. For ROC analysis, adequate cough was defined when PCF $>160 \mathrm{~L} / \mathrm{min}$. Data are presented as mean \pm standard deviation (SD) unless otherwise specified. The $95 \%$ confidence interval of the area under the normalized ROC curve (AUC) and the optimal cut-off point were also computed as described by Hanley and McNeil. ${ }^{19}$ The level of significance was set at $P<0.05$ for all statistical analyses.

\section{RESULTS}

\section{Clinical Data}

Patients belonging to the three groups and healthy subjects were similar in age, height and weight (Table 1). Genetic and clinical characteristics of the patients are reported in Table 2. Noninvasive mechanical ventilation was used only in patients with inefficient cough (PCF $<160 \mathrm{~L} / \mathrm{min}$ ). Cough assistance devices were used in the majority of patients with inefficient cough, in the half of patient with $160<\mathrm{PCF}<270 \mathrm{~L} / \mathrm{min}$ and one-third of patients with $\mathrm{PCF}>270 \mathrm{~L} / \mathrm{min}$. At least one episode of pneumonia or upper airway infection in the year preceding the study occurred in the majority of patients with inefficient cough, and in half of the patients belonging to the other two groups. All patients had scoliosis, mostly severe in patients with inefficient cough, moderate in patients with $160<\mathrm{PCF}<270 \mathrm{~L} / \mathrm{min}$ and mild in patients with PCF $>270 \mathrm{~L} / \mathrm{min}$. Spinal fusion was present only in patients with inefficient cough. The percentage of patients with heart dysfunction and under steroids treatment was similar in the three considered groups.

\section{Respiratory Function Data}

Inefficient cough was associated to worse spirometric parameters (namely, $\mathrm{FVC}$ and $\mathrm{FEV}_{1}$ ), reduced inspiratory capacity, expiratory reserve volume, TLC expressed as percentage of predicted value and maximal pressures (Table 3 and Fig. 3). No differences in the three groups were found in oxygen saturation during night.

\section{Chest Wall Volume Variations}

As shown in Figure 4, in patients with inefficient cough the volume of the total chest wall $(0.97 \pm 0.1 \mathrm{~L})$ was significantly reduced compared to healthy controls $(1.84 \pm 0.2 \mathrm{~L})$ at the end of the inspiration preceding 
TABLE 1-Characteristics of Duchenne Muscular Dystrophy Patients With Inefficient Cough (PCF $<160$ L/min), Adequate Cough When They Are Well (160 $<$ PCF $<270$ L/min), Adequate Cough (PCF $>270$ L/min), and Healthy Controls Data Are Expressed as Mean \pm SD

\begin{tabular}{lcccc}
\hline & PCF $<160 \mathrm{~L} / \mathrm{min}$ & $160<\mathrm{PCF}<270 \mathrm{~L} / \mathrm{min}$ & $\mathrm{PCF}>270 \mathrm{~L} / \mathrm{min}$ & Healthy subjects \\
\hline N. patients & 16 & 12 & 9 & 15 \\
Age $(\mathrm{yrs})$ & $17.6 \pm 4.9$ (range: $10-26)$ & $16.9 \pm 6.0$ (range: $9-31)$ & $16.1 \pm 4.0$ (range: $10-22)$ & $16.3 \pm 5.4$ (range: $9-28$ ) \\
Height $(\mathrm{cm})$ & $161.6 \pm 10.0$ & $157.7 \pm 16.4$ & $159.8 \pm 16.8$ & $168.3 \pm 17.6$ \\
Weight $(\mathrm{kg})$ & $56.9 \pm 11.8$ & $66.0 \pm 22.1$ & $56.1 \pm 22.2$ & $62.3 \pm 24.4$ \\
BMI & $21.8 \pm 4.2$ & $25.5 \pm 5.0$ & $21.6 \pm 6.3$ & $21.1 \pm 5.0$ \\
\hline
\end{tabular}

Body Mass Index computed as BMI $=$ weight $[\mathrm{kg}] /(\text { height }[\mathrm{m}])^{2}$

cough maneuver and this was due to the reduced inspired volumes of both rib cage and abdomen. Conversely, in patients with $\mathrm{PCF}>270 \mathrm{~L} / \mathrm{min}$ total $(1.39 \pm 0.2 \mathrm{~L})$ and compartmental inspired volumes preceding cough were not significantly different than controls. In patients with $160<\mathrm{PCF}<270 \mathrm{~L} / \mathrm{min}$, chest wall inspired volume $(1.11 \pm 0.1 \mathrm{~L})$ was similar to controls, but the abdominal compartment expanded less than controls.

During the period of spontaneous quiet breathing preceding cough maneuvers, all DMD patients showed a reduced tidal volume (Fig. 5, left), however, only patients with inefficient cough did show an abdominal contribution to tidal volume significantly lower than both patients with adequate cough and healthy controls (Fig. 5, right).

Figure 6 shows rib cage, abdominal and total chest wall volume variations in representative cases of patients' and control groups.

\section{Receiver Operating Characteristic (ROC) Analysis}

The ROC curve, the area under the ROC curve (AUC) and the optimal cut-off point (COP), of each parameter that resulted significantly different between inefficient and adequate cough in DMD are shown in Figure 7. These included FVC, $\mathrm{FEV}_{1}$, and TLC expressed as percentage of predicted value (FVC (\% pred), $\mathrm{FEV}_{1}(\%$ pred), and TLC (\%pred), respectively); MIP and MEP; abdominal percentage contribution to inspiratory cough phase, $\Delta \mathrm{V}_{\mathrm{AB}}(\% \mathrm{ICP})$; the abdominal percentage contribution to tidal volume, $\Delta \mathrm{V}_{\mathrm{AB}}\left(\% \mathrm{~V}_{\mathrm{T}}\right)$.

The highest AUC was found for the abdominal percentage contribution to tidal volume, $\Delta \mathrm{V}_{\mathrm{AB}}\left(\% \mathrm{~V}_{\mathrm{T}}\right)$ and its corresponding curve was the closest to the upper left corner compared to all the other curves for any value of sensitivity and specificity.

TABLE 2-Clinical Characteristics of Duchenne Muscular Dystrophy Patients With Inefficient (PCF $<160$ L/min), Adequate Cough When They Are Well (160 $<$ PCF $<270 \mathrm{~L} / \mathrm{min})$, and Adequate Cough (PCF $>270 \mathrm{~L} / \mathrm{min}$ )

\begin{tabular}{|c|c|c|c|}
\hline & $\mathrm{PCF}<160 \mathrm{~L} / \mathrm{min}$ & $160<\mathrm{PCF}<270 \mathrm{~L} / \mathrm{min}$ & $\mathrm{PCF}>270 \mathrm{~L} / \mathrm{min}$ \\
\hline Total number of patients & 16 & 12 & 9 \\
\hline \multicolumn{4}{|l|}{ Genetics } \\
\hline Deletion & 14 & 9 & 5 \\
\hline Duplication & 1 & 2 & 2 \\
\hline Point mutation & 0 & 1 & 2 \\
\hline Undefined mutation & 1 & 0 & 0 \\
\hline Noninvasive mech. ventilation & $6(5 \mathrm{R} / 1 \mathrm{I})$ & 0 & 0 \\
\hline Use of cough assisted devices & $13(10 \mathrm{R} / 3 \mathrm{I})$ & $6(6 \mathrm{R})$ & $3(3 \mathrm{R})$ \\
\hline \multicolumn{4}{|l|}{ Respiratory tract infections in the last year } \\
\hline Upper airways & 2 & 3 & 3 \\
\hline Lower airways & 9 (1 ICU) & 3 & 2 \\
\hline Steroids treatment & 8 & 7 & 5 \\
\hline Heart dysfunction $(\mathrm{LVEF}<50 \%)$ & 9 & 5 & 5 \\
\hline \multicolumn{4}{|l|}{ Scoliosis } \\
\hline Severe $\left(\right.$ Cobb angle $\left.>40^{\circ}\right)$ & 8 & 1 & 1 \\
\hline Moderate $\left(20^{\circ}<\mathrm{Cobb}\right.$ angle $\left.<40^{\circ}\right)$ & 5 & 7 & 3 \\
\hline Mild (Cobb angle $<20^{\circ}$ ) & 0 & 4 & 5 \\
\hline Spinal fusion & 3 & 0 & 0 \\
\hline
\end{tabular}

Each value refers to the number of patients. LVEF, left ventricular ejection fraction; R, use on a routine basis; I: use only during an infection; ICU, intensive care unit hospitalization required. 
TABLE 3-Pulmonary Function Test and Respiratory Muscles Performance in Duchenne Muscular Dystrophy Patients With Inefficient Cough (PCF $<160$ L/min), Adequate Cough When They Are Well $(160<$ PCF $<270$ L/min) and Adequate Cough (PCF $>270 \mathrm{~L} / \mathrm{min})$

\begin{tabular}{|c|c|c|c|}
\hline & $\mathrm{PCF}<160 \mathrm{~L} / \mathrm{min}$ & $160<\mathrm{PCF}<270 \mathrm{~L} / \mathrm{min}$ & $\mathrm{PCF}>270 \mathrm{~L} / \mathrm{min}$ \\
\hline \multicolumn{4}{|l|}{ Spirometry } \\
\hline $\mathrm{n}$ & 15 & 11 & 9 \\
\hline FVC (L) & $1.2 \pm 0.6^{\circ}$ & $1.5 \pm 0.5$ & $2.3 \pm 1.1$ \\
\hline FVC (\% pred) & $35 \pm 20^{\circ \circ}$ & $48 \pm 28$ & $64 \pm 29$ \\
\hline $\mathrm{FEV}_{1}(\mathrm{~L})$ & $1.0 \pm 0.6^{\circ \circ}$ & $1.2 \pm 0.5^{\circ}$ & $1.7 \pm 0.7$ \\
\hline $\mathrm{FEV}_{1}(\%$ pred $)$ & $35 \pm 23^{\circ}$ & $45 \pm 32$ & $62 \pm 35$ \\
\hline $\mathrm{FEV}_{1} / \mathrm{FVC}(\%)$ & $84 \pm 15$ & $77 \pm 17$ & $79 \pm 18$ \\
\hline PEF (L) & $2.2 \pm 0.9$ & $2.6 \pm 1.1$ & $3.3 \pm 1.5$ \\
\hline PEF (\%pred) & $31 \pm 17$ & $41 \pm 25$ & $52 \pm 31$ \\
\hline \multicolumn{4}{|l|}{ Lung volumes } \\
\hline $\mathrm{n}$ & 14 & 11 & 8 \\
\hline TLC (\%pred) & $52 \pm 24^{\circ}$ & $67 \pm 49$ & $76 \pm 27$ \\
\hline RV (\%pred) & $105 \pm 63$ & $131 \pm 159$ & $112 \pm 28$ \\
\hline RV/TLC (\%) & $49 \pm 16$ & $42 \pm 14$ & $36 \pm 9$ \\
\hline FRC $\mathrm{N}_{2}$ (\%pred) & $64 \pm 33$ & $87 \pm 90$ & $87 \pm 29$ \\
\hline \multicolumn{4}{|c|}{ Nocturnal $\mathrm{SpO}_{2}(\%$ night time $)$} \\
\hline $\mathrm{n}$ & 15 & 12 & 8 \\
\hline $95 \%<\mathrm{SpO}_{2}<100 \%$ & $82 \pm 27$ & $89 \pm 25$ & $85 \pm 27$ \\
\hline $90 \%<\mathrm{SpO}_{2}<94 \%$ & $11 \pm 17$ & $10 \pm 24$ & $15 \pm 27$ \\
\hline $\mathrm{SpO}_{2}<90 \%$ & $0.5 \pm 1$ & $1 \pm 2$ & $0 \pm 0$ \\
\hline \multicolumn{4}{|c|}{ Respiratory muscles pressures } \\
\hline $\mathrm{n}$ & 13 & 11 & 8 \\
\hline $\mathrm{MIP}\left(\mathrm{cmH}_{2} \mathrm{O}\right)$ & $19 \pm 9^{\circ, \#}$ & $30 \pm 7$ & $35 \pm 16$ \\
\hline $\operatorname{MEP}\left(\mathrm{cmH}_{2} \mathrm{O}\right)$ & $22 \pm 12^{\circ}$ & $30 \pm 11$ & $36 \pm 12$ \\
\hline
\end{tabular}

Data are expressed as mean \pm SD. n, number of patients with available data; FVC, forced vital capacity; $\mathrm{FEV}_{1}$, forced expiratory volume in 1 sec; PEF, peak expiratory flow; TLC, total lung capacity; RV, residual volume; FRC $\mathrm{N}_{2}$, functional residual capacity measured by $\mathrm{N}_{2}$ washout; $\mathrm{SpO}_{2}$, arterial oxygen saturation measured by pulse oxymetry; MIP, maximal inspiratory pressure; MEP, maximal expiratory pressure; \%pred, percentage of predicted value.

${ }^{\circ},{ }^{\circ} P<0.05, P<0.01$ (vs. PCF $>270 \mathrm{~L} / \mathrm{min}$ ).

${ }^{\#} P<0.05$ (vs. $\left.160<\mathrm{PCF}<270 \mathrm{~L} / \mathrm{min}\right)$.

\section{DISCUSSION}

To the best of our knowledge, this study is the first that specifically examines how the pattern of total and compartmental chest wall volume variations measured during cough and spontaneous breathing are linked to cough effectiveness in DMD patients. We have shown that the volume inspired prior to coughing is significantly reduced in patients with inefficient cough and that the abdominal contribution to tidal volume during spontaneous breathing is a strong predictor of cough efficiency in DMD patients.

The inspired volume preceding coughing is important because it determines not only the volume of air that can be expelled but also the length-tension relationship of the expiratory muscles, that is their ability of producing force. In DMD the weakness of the inspiratory muscles is therefore an important limiting factor of cough efficacy, as it reduces the inspired volume before cough maneuver. ${ }^{3-4}$

Previous studies have postulated the relationship between inspired volume and cough efficiency on the basis of correlation analysis between peak cough flow and other functional variables as MIP, MEP, FVC, and
$\mathrm{FEV}_{1}{ }^{6,7}$ made on pooled data. Differently, in the present study we have grouped our cohort of DMD patients according to cough efficiency clinically assessed by PCF. Successively, we studied which parameters significantly differed among groups, considering in our analysis not only the traditional spirometric and MIP/MEP evaluation, but also total and compartmental chest wall volume variations during cough maneuver and spontaneous breathing assessed by opto-electronic plethysmography.

Our results indicate that the pattern of chest wall volumes changes significantly differs between groups with efficient and inefficient cough, during not only coughing but also spontaneous breathing. While total chest wall volume variation during inspiration preceding cough was significantly lower than controls only in patients with inefficient cough, tidal volume during spontaneous breathing was lower in all DMD patients. This means that total chest wall volume variations (reflecting lung volume variations) can discriminate the efficiency of cough only when considering the cough maneuver per se. Conversely, when considering volume variations of the two chest wall compartments, namely the rib cage and the abdomen, significant differences are 


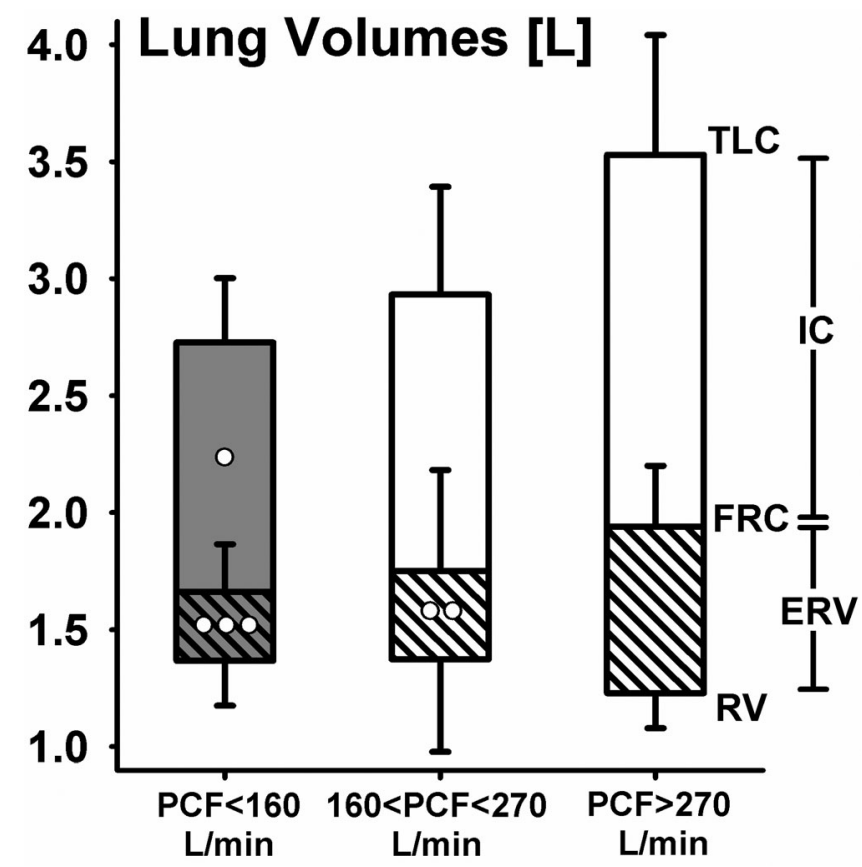

Fig. 3. Average values \pm SE of absolute (TLC, total lung capacity; FRC, functional residual capacity; RV, residual volume) and relative (IC, inspiratory capacity; ERV, expiratory reserve volume) lung volumes in DMD patients with inefficient (grey), and adequate (white) cough. Dashed areas indicate ERV. ${ }^{\circ},{ }^{\circ} \mathrm{P}<\mathbf{0 . 0 5},<\mathbf{0 . 0 1},<\mathbf{0 . 0 0 1}$ (vs. PCF $>270 \mathrm{~L} / \mathrm{min}$ ).

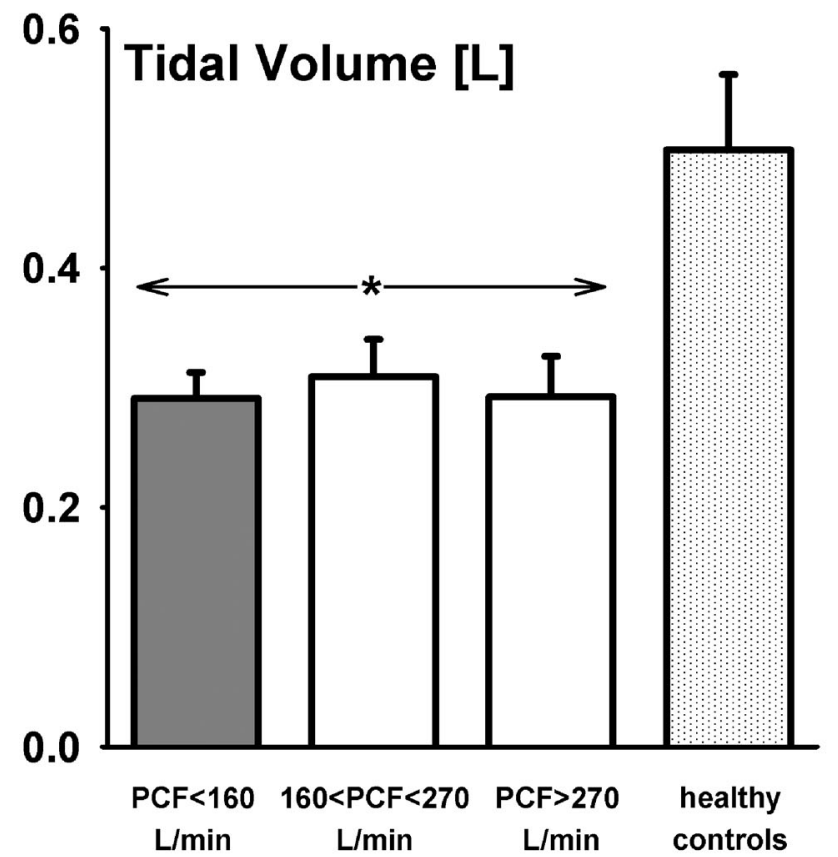

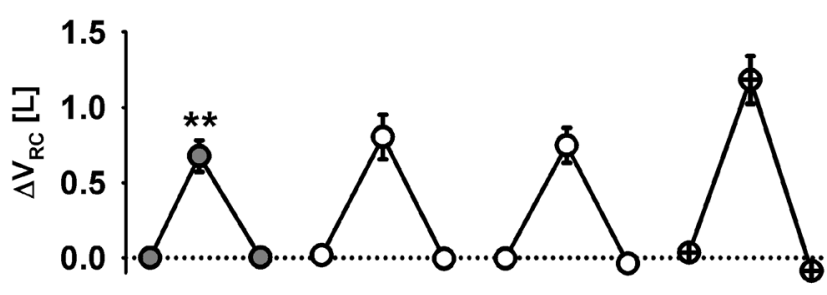
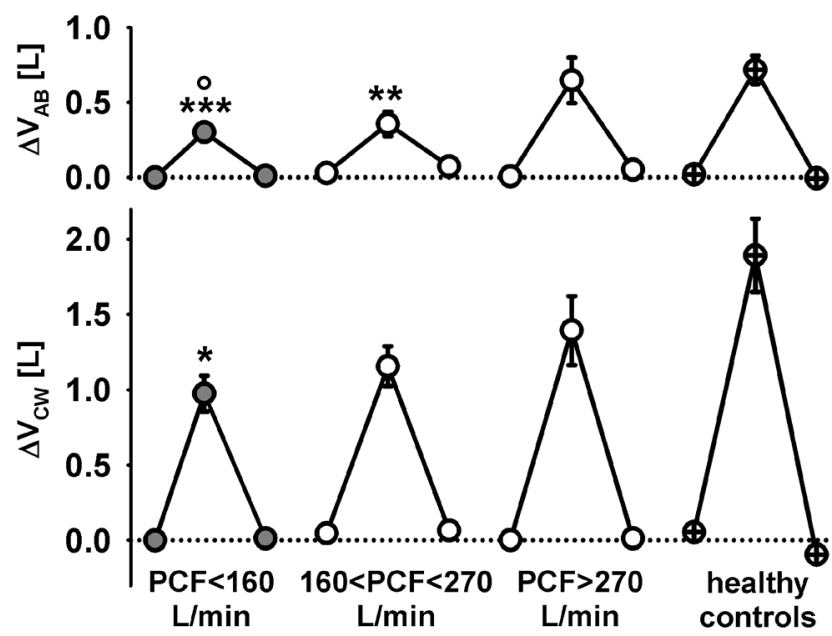

Fig. 4. Average values \pm SE of $\Delta V_{R C}$ (top panel), $\Delta V_{A B}$ (middle), and $\Delta \mathbf{V}_{\mathrm{CW}}$ (bottom) at start of inspiration, end of inspiration and end of cough in DMD patients with ineffective cough (close symbols), adequate cough (open symbols) and controls (crossed symbol). ${ }^{*},{ }^{* *},{ }^{* * *} \boldsymbol{P}<0.05, \boldsymbol{P}<0.01, \boldsymbol{P}<0.001$ (vs. controls) ${ }^{\circ} P<0.05$ (vs. PCF $>270 \mathrm{~L} / \mathrm{min}$ ).

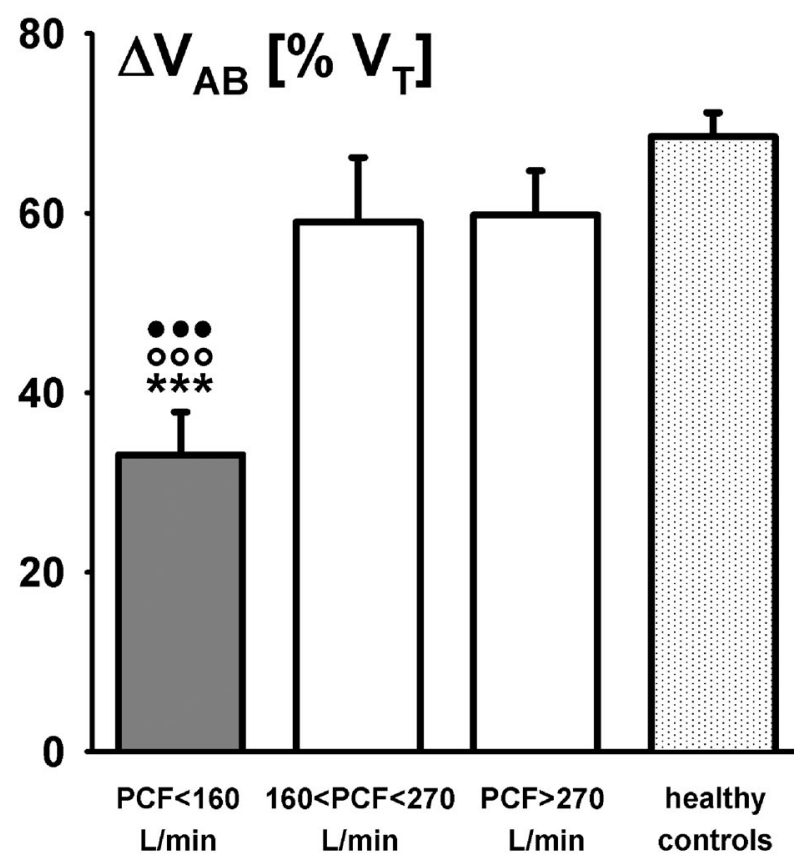

Fig. 5. Average values \pm SE of tidal volume (left panel) and its abdominal percentage contribution (right) during quiet breathing preceding cough in DMD patients with ineffective cough (grey bars), adequate cough (white bars) and controls (dotted bars). ${ }^{*},{ }^{* * *} \boldsymbol{P}<\mathbf{0 . 0 5}, 0.001$ (vs. controls) ${ }^{\circ 0} P<0.001$ (vs. PCF $>270 \mathrm{~L} / \mathrm{min}$ ). ${ }^{\# \# \#} P<0.001$ (vs. $160<$ PCF $<270 \mathrm{~L} / \mathrm{min}$ ). 

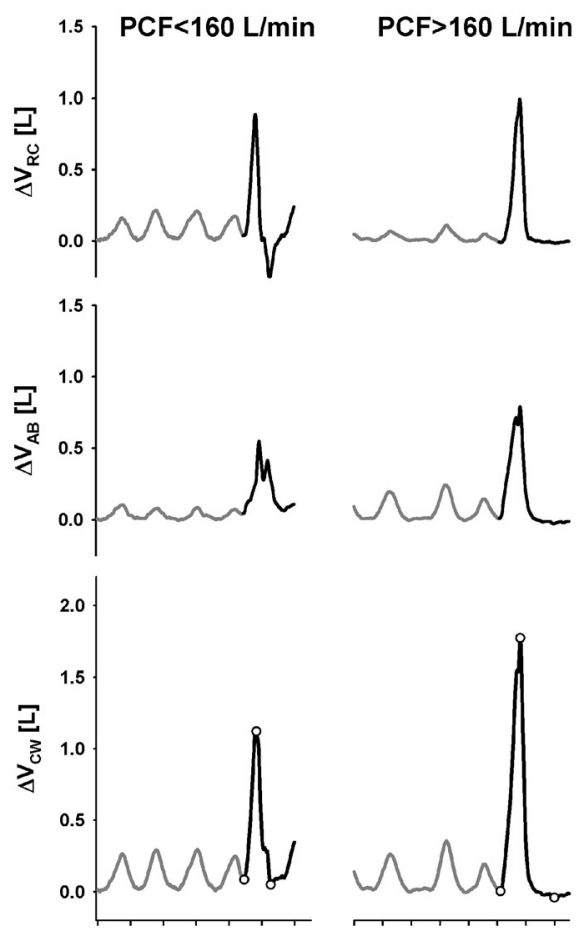

Fig. 6. Representative cases of $\Delta V_{R C}$ (upper panels), $\Delta V_{A B}$ (middle), and $\Delta V_{C W}$ (lower) during spontaneous breathing and a single cough in patients with $\mathrm{PCF}<160 \mathrm{~L} / \mathrm{min}, \mathrm{PCF}>270 \mathrm{~L} / \mathrm{min}$ and controls. DMD tidal volume is similar but lower than controls. With increasing cough efficiency, $\Delta V_{A B}$ increases and $\Delta V_{R C}$ decreases and inspired cough volume increases.

present also during quiet breathing. In fact, patients with $\mathrm{PCF}<160 \mathrm{~L} / \mathrm{min}$ have a strongly reduced abdominal contribution to tidal volume compared not only to controls but also to patients with efficient cough. In addition, during the inspiration preceding cough, abdominal volume changes are helpful to distinguish between the two groups with efficient cough (PCF $>160 \mathrm{~L} / \mathrm{min}$ ). In fact, patients with efficient cough only when they are well $(160<\mathrm{PCF}<270 \mathrm{~L} / \mathrm{min})$ have reduced contribution of abdomen to inspired volume, suggesting inefficiency of inspiratory muscles.

These results regarding abdominal volume indicate that what really determines cough efficiency is diaphragm contribution to volume displacement both during quiet breathing and inspiration preceding cough. Conversely, the results regarding rib cage volume variations suggest that in patients with inefficient cough, inspiratory rib cage muscles are weakened to a lesser extent and during quiet breathing they compensate the reduced action of the impaired diaphragm.

An important implication of our study is that standard measurements of ventilation at the mouth (e.g., provided by a flowmeter) are not useful in order to discriminate between patients with and without efficient cough. On the other hand, accurate measurements of thoraco-abdominal volume variations are able to predict cough efficiency even during quiet breathing without requiring neither patient's cooperation nor the use of a mouthpiece.

Recently, our group showed that in DMD patients abdominal contribution to volume variations in supine position is a parameter that tracks the progressive diaphragmatic impairment. ${ }^{12}$ In addition, it allows to discriminate between adolescents and adult patients who present either no signs or only mild nocturnal oxygen desaturation $^{13}$ with an optimal cut-off point for $\Delta \mathrm{V}_{\mathrm{AB}}$ $\left(\% \mathrm{~V}_{\mathrm{T}}\right)$ equal to $36.2 \%$. In the present study we have shown that abdominal volume variations are also able to discriminate patients with and without efficient cough (optimal cut-off equal to 46\%). The difference in the cutoff values of abdominal contribution can be explained by considering that in the progression of the disease the occurrence of cough inefficiency precedes the early signs of nocturnal oxygen desaturation when the diaphragm, and consequently abdominal volume contribution, is less compromised. In contrast, we found very similar cut-off thresholds for FVC(\% pred), respectively $31 \%$ and $30.5 \%$. Interestingly, a cut-off threshold of $30 \%$ for $\mathrm{FVC}(\%$ pred) has also been found in another recent study to identify patients at high risk for severe chest infections. ${ }^{1}$ All these data suggest that FVC(\%pred), although largely adopted in clinical practice, cannot directly be linked to the mechanisms underlying the progressive loss of cough efficiency and the onset of nocturnal oxygen desaturation, for which the weakness of inspiratory muscles plays an important role. Abdominal volume contribution to inspired volume, therefore, can help to determine when treatment should be started, either cough assisting devices or noninvasive ventilation, or if further evaluation is required.

The relatively low number of subjects could represent a limitation of this work, although our cohort is composed of only patients with DMD homogeneous in age, anthropometric parameters, and clinical history. We did not include young children because they are not able to perform reliable voluntary maneuvers like spirometry and therefore we would not have all the parameters available for the data analysis. On the other hand, in our cohort of patients we do not have any DMD patient with tracheostomy since NIV and regular application of in-exsufflator avoid severe complications causing tracheostomy. ${ }^{20}$ Another possible limitation is that OEP technique, although widely validated in previous studies in healthy and pathological subjects, is not yet largely diffused into clinics. The great advantage of OEP, however, is that accurate measurements of thoracoabdominal volumes by OEP can be obtained noninvasively and with non-volitional tests.

In conclusion, we have shown that inefficient cough in DMD is associated to reduced operating lung and chest wall volume secondary to weakened inspiratory muscles. 

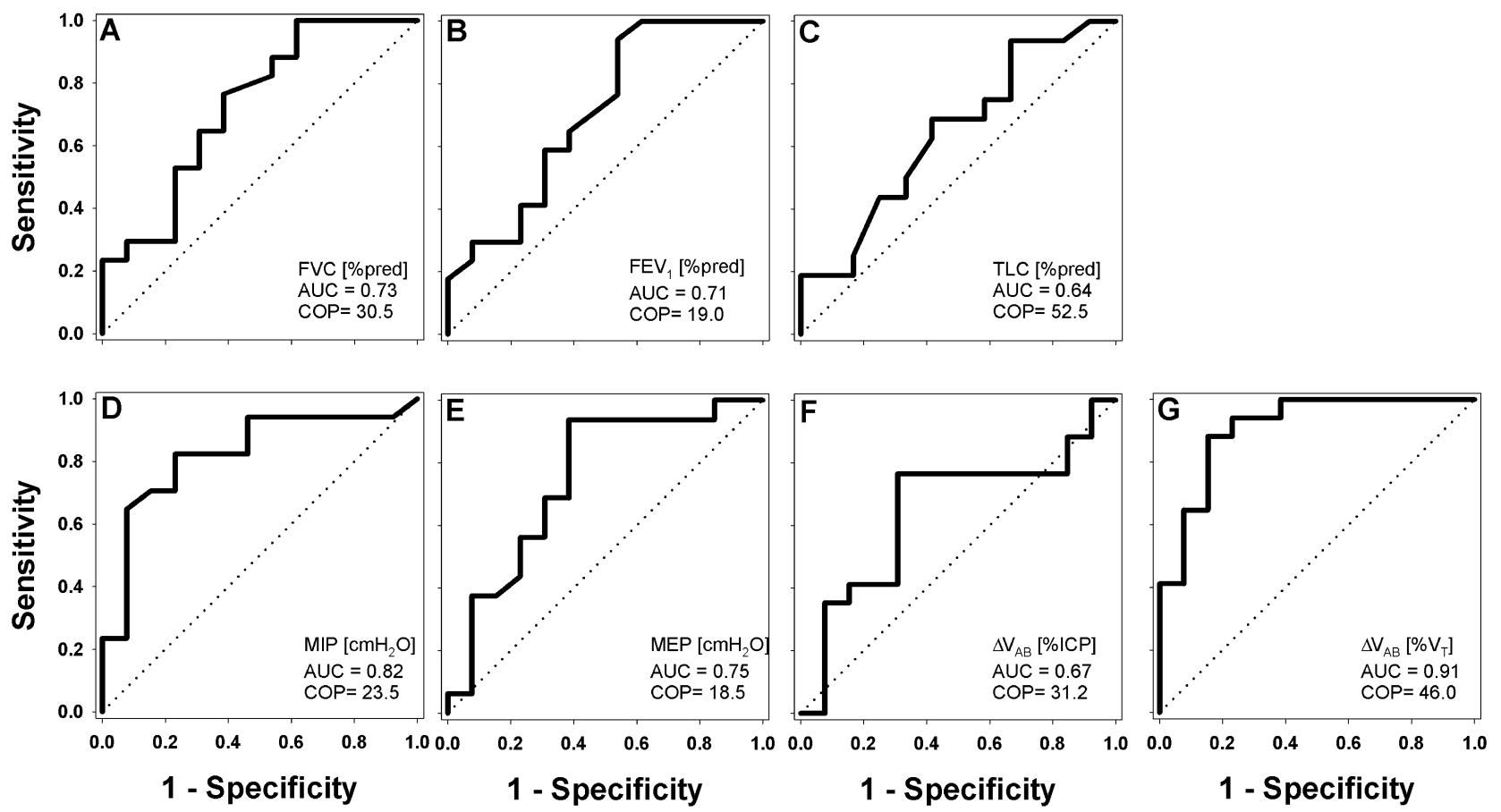

Fig. 7. ROC curves of Maximal Inspiratory Pressure (MIP), Maximal Expiratory Pressure (MEP), abdominal contribution to Inspiratory Cough Phase $\left(\Delta \mathrm{V}_{\mathrm{AB}}[\% \mathrm{ICP}]\right)$ and to tidal volume $\left(\Delta \mathrm{V}_{\mathrm{AB}}\left[\% \mathrm{~V}_{\mathrm{T}}\right]\right)$, predicted Forced Vital Capacity (FVC [\%pred]), Forced Expired Volume in one second (FEV ${ }_{1}[\%$ pred]) and Total Lung Capacity (TLC[\%pred]) considering cough adequate when PCF $>160 \mathrm{~L} / \mathrm{min}$, inefficient when PCF $<160 \mathrm{~L} / \mathrm{min}$. AUC, area under the curve; COP, optimal cut-off point.

In addition, abdominal contribution to tidal volume during spontaneous breathing represents a non-volitional and noninvasive index able to discriminate efficient and inefficient cough.

\section{ACKNOWLEDGMENT}

The authors are grateful to the patients and their parents for the collaboration. This work was supported by a grant of Fondo DMD “Amici di Emanuele".

\section{REFERENCES}

1. Dohna-Schwake C, Ragette R, Teschler H, Voit T, Mellies U. Predictors of severe chest infections in pediatric neuromuscular disorders. Neuromuscul Disord 2006;16:325-328.

2. Bushby K, Finkel R, Birnkrant DJ, Care DMD. Working Considerations Group. Diagnosis and management of Duchenne muscular dystrophy, part 1: diagnosis, and pharmacological and psychosocial management. Lancet Neurol 2010;9:77-93.

3. Trebbia G, Lacombe M, Fermanian C, Falaize L, Lejaille M, Louis A, Devaux C, Raphaël JC, Lofaso F. Cough determinants in patients with neuromuscular disease. Respir Physiol Neurobiol 2005;146:291-300

4. Kravits RM. Airway clearance in Duchenne muscular dystrophy. Pediatrics 2009;123:S231-S235.

5. Gauld LM, Boynton A. Relationship between peak cough flow and spirometry in Duchenne muscular dystrophy. Pediatr Pulmonol 2005;39:457-460.
6. Kang SW, Kang YS, Sohn HS, Park JH, Moon JH. Respiratory muscle strength, cough capacity in patients with Duchenne muscular dystrophy. Yonsei Med J 2006;47:184-190.

7. Park JH, Kang SW, Lee SC, Choi WA, Kim DH. How respiratory muscle strength correlates with cough capacity in patients with respiratory muscle weakness. Yonsei Med J 2010;51:392-397.

8. Nicot F, Hart N, Forin V, Boulé M, Clément A, Polkey MI, Lofaso F, Fauroux B. Respiratory muscle testing: a valuable tool for children with neuromuscular disorders. Am J Respir Crit Care Med 2006;174:67-74.

9. Bach JR, Saporito LR. Criteria for extubation and tracheostomy tube removal for patients with ventilatory failure. A different approach to weaning. Chest 1996;110:1566-1571.

10. Man WDC, Kyroussis D, Fleming TA, Chetta A, Harraf F, Mustfa N, Rafferty GF, Polkey MI, Mowham J. Cough gastric pressure and maximum expiratory mouth pressure in humans. Am J Respir Crit Care Med 2003;168:714-717.

11. Smith JA, Aliverti A, Quaranta M, McGuinness K, Kelsall A, Earis J, Calverley PM. Chest wall dynamics during voluntary and induced cough in healthy volunteers. J Physiol 2012;590:563-574.

12. Lo Mauro A, D'Angelo MG, Romei M, Colombo D, Comi GP, Pedotti A, Marchi E, Turconi AC, Bresolin N, Aliverti A. Abdominal volume contribution to tidal volume as an early indicator of respiratory impairment in Duchenne muscular dystrophy. Eur Respir J 2010;35:1118-1125.

13. Romei M, D'Angelo MG, LoMauro A, Gandossini S, Bonato S, Brighina E, Marchi E, Comi GP, Turconi AC, Pedotti A, et al. Low abdominal contribution to breathing as daytime predictor of nocturnal desaturation in adolescents and young adults with Duchenne Muscular Dystrophy. Respir Med 2012;106:276-283. 
14. Finder JD, Birnkrant D, Carl J, Farber HJ, Gozal D, Iannaccone ST, Kovesi T, Kravitz RM, Panitch H, Schramm C, et al. American Thoracic Society. Respiratory care of the patient with Duchenne muscular dystrophy: ATS consensus statement. Am J Respir Crit Care Med 2004;170:456-465, Review.

15. American Thoracic Society/European Respiratory Society. ATS/ ERS statement on respiratory muscle testing. Am J Respir Crit Care Med 2002;166:518-624.

16. Miller MR, Hankinson J, Brusasco V, Burgos F, Casaburi R, Coates A, Enright P, van der Grinten C, Gustafsson P, Jensen R, et al. ATS/ERS Task Force. Standardisation of spirometry. Eur Respir J 2005;26:319-338.

17. Miller MR, Crapo R, Hankinson J, Brusasco V, Burgos F, Casaburi R, Coates A, Enright P, van der Grinten CP, Gustafsson P, et al.
ATS/ERS Task Force. General considerations for lung function testing. Eur Respir J 2005;26:153-161, Review.

18. Quanjer PH, Tammeling GJ, Cotes JE, Pedersen OF, Peslin $\mathrm{R}$, Yernault JC, et al. Lung volumes and forced ventilatory flows. Report working party standardization of lung function tests, European community for steel and coal. Official Statement of the European Respiratory Society. Eur Respir J 1993;16: $5-40$.

19. McNeil BJ, Hanley JA. Statistical approaches to the analysis of receiver operating characteristic (ROC) curves. Med Decis Making 1984;4:137-150.

20. Tzeng AC, Bach JR. Prevention of pulmonary morbidity for patients with neuromuscular disease. Chest 2000;118:1390 1396. 